\title{
Neuroinflammation Leads to Region-Dependent Alterations in Astrocyte Gap Junction Communication and Hemichannel Activity
}

\author{
Nikolay Karpuk, ${ }^{\star}$ Maria Burkovetskaya, ${ }^{\star}$ Teresa Fritz, Amanda Angle, and Tammy Kielian \\ Department of Pathology and Microbiology, University of Nebraska Medical Center, Omaha, Nebraska 68198
}

Inflammation attenuates gap junction (GJ) communication in cultured astrocytes. Here we used a well-characterized model of experimental brain abscess as a tool to query effects of the CNS inflammatory milieu on astrocyte GJ communication and electrophysiological properties. Whole-cell patch-clamp recordings were performed on green fluorescent protein (GFP)-positive astrocytes in acute brain slices from glial fibrillary acidic protein-GFP mice at 3 or $7 \mathrm{~d}$ after Staphylococcus aureus infection in the striatum. Astrocyte GJ communication was significantly attenuated in regions immediately surrounding the abscess margins and progressively increased to levels typical of uninfected brain with increasing distance from the abscess proper. Conversely, astrocytes bordering the abscess demonstrated hemichannel activity as evident by enhanced ethidium bromide $(\mathrm{EtBr})$ uptake that could be blocked by several pharmacological inhibitors, including the connexin 43 (Cx43) mimetic peptide Gap26, carbenoxolone, the pannexin1 (Panx1) mimetic peptide ${ }^{10} \mathrm{Panx} 1$, and probenecid. However, hemichannel opening was transient with astrocytic EtBr uptake observed near the abscess at day 3 but not day 7 after infection. The region-dependent pattern of hemichannel activity at day 3 directly correlated with increases in Cx43, Cx30, Panx1, and glutamate transporter expression (glial L-glutamate transporter and L-glutamate/L-aspartate transporter) along the abscess margins. Changes in astrocyte resting membrane potential and input conductance correlated with the observed changes in GJ communication and hemichannel activity. Collectively, these findings indicate that astrocyte coupling and electrical properties are most dramatically affected near the primary inflammatory site and reveal an opposing relationship between the open states of GJ channels versus hemichannels during acute infection. This relationship may extend to other CNS diseases typified with an inflammatory component.

\section{Introduction}

Astrocytes form syncytial networks within the CNS through gap junction (GJ) communication to influence expansive parenchymal domains (Konietzko and Müller, 1994; Sutor and Hagerty, 2005; Houades et al., 2008). Gap junctions are formed by the joining of two hemichannels between adjacent cells each composed of six connexin $(\mathrm{Cx})$ subunits. Astrocytic GJ are capable of transmitting a wide variety of small molecules $(<1 \mathrm{kDa})$ depending on their molecular shape and charge, including glutamate, ATP, glucose, $\mathrm{Ca}^{2+}, \mathrm{K}^{+}$, and $\mathrm{Na}^{2+}$, and, as such, play a vital role in maintaining ionic and metabolic stability in the CNS parenchyma (Rose and Ransom, 1997; Tabernero et al., 2006; Cruz et al., 2007; Figiel et al., 2007; Harris, 2007; Rouach et al., 2008; Gandhi et al., 2009). Astrocyte hemichannels can be formed by two distinct families, namely Cxs and pannexins (Panx). These proteins have similar membrane topology but minimal amino acid homology and exhibit differences in unitary conductance

Received 0ct. 6, 2010; accepted 0ct. 23, 2010.

This work was supported by National Institutes of Health/National Institute of Neurological Disorders and Stroke Grant R01 NS053487 (T.K.). We thank Vladimir Parpura and Kevin Phelan for critical review of this manuscript.

${ }^{*} N . K$. and M.B. contributed equally to this work.

Correspondence should be addressed to Dr. Tammy Kielian, University of Nebraska Medical Center, Department of Pathology and Microbiology, 985900 Nebraska Medical Center, Omaha, NE 68198-5900. E-mail: tkielian@unmc.edu.

D0I:10.1523/JNEUROSCI.5247-10.2011

Copyright $\odot 2011$ the authors $\quad 0270-6474 / 11 / 310414-12 \$ 15.00 / 0$ and half-life (Baranova et al., 2004; Yen and Saier, 2007; Thompson and Macvicar, 2008; D'hondt et al., 2009). In addition, Cx hemichannels are regulated by $\mathrm{Ca}^{2+}, \mathrm{pH}$ changes, or altered membrane potential (D'hondt et al., 2009), whereas Panx1 hemichannels are sensitive to $\mathrm{K}^{+}$but refractive to $\mathrm{Ca}^{2+}$ and linked to the ionotropic $\mathrm{P} 2 \mathrm{X}_{7}$ receptor, which leads to channel opening in response to extracellular ATP (Dubyak, 2009; Iglesias et al., 2009; Qiu and Dahl, 2009).

Astrocytes undergo a series of complex changes in response to a wide variety of pathological insults, known as astrogliosis, during which their morphological, electrophysiological, and biochemical properties may be altered. For example, a rapid increase in glial fibrillary acidic protein (GFAP) expression and cellular hypertrophy are hallmarks of activated astrocytes (Nolte et al., 2001). Other features include alterations in glutamate metabolism and glucose uptake (Liberto et al., 2004; Tabernero et al., 2006). Dramatic changes in GJ communication have been reported in activated astrocytes, which correlate with alterations in Cx expression (Chanson et al., 2005; Giaume et al., 2007; Scemes et al., 2007; Kielian, 2008). In addition, proinflammatory cytokines, such as tumor necrosis factor- $\alpha$ (TNF- $\alpha$ ) and interleukin-1 $\beta$ (IL-1 $\beta$ ), can attenuate Cx43 expression and GJ communication in astrocytes (John et al., 1999; Haghikia et al., 2008) and astrocyte-microglia cocultures (Hinkerohe et al., 2005; Même et al., 2006), and previous studies from our laboratory have demonstrated that exposure to the Gram-positive bacte- 
rium Staphylococcus aureus leads to reductions in astrocyte GJ communication (Esen et al., 2007).

Although stimuli used to model pathological insults in vitro, such as extracellular glutamate or ATP, low extracellular $\mathrm{Ca}^{2+}$, hypoxia, hypoglycemia, or acidification, cause rapid hemichannel opening in cultured cells (Contreras et al., 2002; Ye et al., 2003; De Vuyst et al., 2006; Retamal et al., 2007a; Shintani-Ishida et al., 2007), little is currently known regarding the functional importance of hemichannels in situ or in vivo during various pathological conditions. $\mathrm{P}_{2} \mathrm{X}_{7}$ receptor activation induces $\mathrm{Panx} 1$ hemichannel opening in astrocytes (Scemes et al., 2007; Iglesias et al., 2009) and in macrophages leads to caspase- 1 activation and subsequent processing and release of IL-1 $\beta$ (Pelegrin and Surprenant, 2006, 2009). Moreover, Panxl hemichannel activity has been implicated recently in inflammasome formation in cultured neurons and astrocytes (Silverman et al., 2009).

The objective of the current study was to examine the effects of neuroinflammation on astrocyte GJ and hemichannel activity as well as electrophysiological properties using a well-established model of bacterial brain abscess developed in our laboratory (Kielian et al., 2001, 2007a,b). Whole-cell voltage- and currentclamp recordings were used to measure properties of striatal astrocytes at varying distances from the abscess in acute brain slices from GFAP-green fluorescent protein (GFP) mice. Astrocytes nearest the abscess margins displayed minimal GJ coupling, which progressively increased with increasing distance from the lesion. The block in astrocyte GJ communication surrounding the abscess coincided with the opening of hemichannels as evidenced by ethidium bromide (EtBr) uptake that could be inhibited by several gap junction/hemichannel blockers. Changes in astrocyte resting membrane potential and input conductance correlated with the observed changes in GJ communication and hemichannel activity. To our knowledge, this is the first report demonstrating functional hemichannel activity in brain slices and Panxl protein expression in astrocytes in situ.

\section{Materials and Methods}

Generation of experimental brain abscesses. Experimental brain abscesses were established in GFAP-GFP mice, in which GFP expression is driven by the human GFAP promoter (Zhuo et al., 1997) (8-12 weeks of age; The Jackson Laboratory) by the intracerebral inoculation of live S. aureus (strain USA300) (Sifri et al., 2007) encapsulated in agarose beads as described previously (Kielian et al., 2004). A rodent stereotaxic apparatus equipped with a Cunningham mouse adaptor (Stoelting) was used to implant $S$. aureus-encapsulated agarose beads into the striatum using the following coordinates relative to bregma: $+1.0 \mathrm{~mm}$ rostral, $+2.0 \mathrm{~mm}$ lateral, and $-3.0 \mathrm{~mm}$ deep from the surface of the brain. These stereotaxic coordinates were taken from the Paxinos and Franklin mouse brain atlas (Paxinos and Franklin, 2001), which reproducibly deposit bacteria into the dorsal striatum. A burr hole was made, and a $5 \mu$ l Hamilton syringe fitted with a 26 gauge needle was used to slowly deliver $2 \mu \mathrm{l}$ beads $\left(1 \times 10^{3}\right.$ colony forming units) into the brain parenchyma over a $30 \mathrm{~s}$ period, and the needle remained in place for $2-3 \mathrm{~min}$ after injection to prevent the efflux of injected material. Earlier studies from our laboratory have established that the introduction of sterile agarose beads does not induce detectable inflammation or peripheral immune cell infiltrates (Baldwin and Kielian, 2004). The animal use protocol, approved by the University of Nebraska Medical Center Institutional Animal Care and Use Committee, is in accord with the National Institutes of Health guidelines for the use of rodents.

Definition of striatal regions analyzed for GJ communication, electrophysiology, immunostaining, and hemichannel activity measurements. All GFAP-GFP-positive (GFAP-GFP ${ }^{+}$) astrocytes analyzed for GJ coupling, electrophysiological, and hemichannel studies were located in the striatum, in which measurements were initiated at the brain abscess bor- der and extended outward for a distance of up to 1-1.5 mm. In uninfected mice, the physical locations of astrocytes corresponded to the same striatum areas as in infected animals to negate any potential influences based on cell position. The brain abscess border was identified as the junction between necrotic and live tissue in which intense GFAP-GFP ${ }^{+}$ astrocytes were visible (Fig. 1C). All distance calculations were performed using AxioVision software (Carl Zeiss). Low-magnification images of brain abscesses were captured with $25 \times-50 \times$ total magnification, whereas all images collected for calculating GJ communication, sulforhodamine 101 (SR101) staining, and hemichannel opening were collected at $400 \times$ total magnification and covered a field of view (FOV) of $164 \times 224$ $\mu \mathrm{m}$. Immunofluorescence images [for Cx43, Cx30, Panx1, glial L-glutamate transporter-1 (GLT-1), and L-glutamate/L-aspartate transporter (GLAST)] were acquired at $200 \times$ total magnification and a FOV of $450 \times 450 \mu \mathrm{m}$ using confocal microscopy.

Acute brain slice preparation. At the appropriate time points for analysis, mice were killed by cervical dislocation and immediately decapitated. The brain was quickly removed and bathed in ice-cold artificial CSF (aCSF) (in mm: $124 \mathrm{NaCl}, 26 \mathrm{NaHCO}_{3}, 3 \mathrm{KCl}, 2 \mathrm{MgCl}_{2}, 2 \mathrm{CaCl}_{2}, 0.4$ ascorbic acid, and 10 glucose) for slice preparation. Next, horizontal slices (300-400 $\mu \mathrm{m}$ thick) were cut using a Leica VT1000S vibratingblade microtome (Leica Microsystems) and immediately placed in aCSF at $32^{\circ} \mathrm{C}$. After a $20-30 \mathrm{~min}$ incubation period at $32^{\circ} \mathrm{C}$, brain slices were held in aCSF at room temperature for at least $1 \mathrm{~h}$ before additional use. All incubation solutions were equilibrated and continuously bubbled with carbogen $\left(95 \% \mathrm{O}_{2}\right.$ and $\left.5 \% \mathrm{CO}_{2}\right)$. In some experiments, slices were incubated with SR101 acid chloride $(0.4 \mu \mathrm{M}$; Sigma) as an additional marker for astrocyte identification.

Electrophysiology. Electrophysiological recordings were performed in a submerged chamber (RC-27; Warner Instruments) continuously perfused with aCSF at a rate of $1-2 \mathrm{ml} / \mathrm{min}$ at $30^{\circ} \mathrm{C}$. Whole-cell voltage- and current-clamp recordings were performed on GFAP-GFP ${ }^{+}$striatal astrocytes using a computer-controlled amplifier (Multiclamp 700B; Molecular Devices) and a video setup equipped with a motorized Axio Examiner Z1 fluorescent microscope, a high-sensitivity and highresolution digital camera (AxioCam MRm), and AxioVision software (all from Carl Zeiss). Patch pipettes for recording electrodes were pulled from borosilicate glass capillaries $(1.5 \mathrm{~mm}$ outer diameter, $0.84 \mathrm{~mm}$ inner diameter) using a micropipette puller (P-97; Sutter Instruments). Recording electrodes were filled with a solution containing the following (in mM): $130 \mathrm{KCI}, 0.2 \mathrm{CaCl}_{2}, 1 \mathrm{MgCI}_{2}, 10 \mathrm{EGTA}$, and $10 \mathrm{HEPES}$ (with an electrical resistance of $6-10 \mathrm{M} \Omega$ ). The GJ-permeable dye Alexa Fluor 350 ( $0.5 \mathrm{~mm}$; Invitrogen) was added to the intracellular recording solution to evaluate cell coupling between astrocytes.

Analog signals from the amplifier were digitized at a $5-10 \mathrm{kHz}$ sampling rate using the Digidata-1440A acquisition system and pClamp-10 software (both from Molecular Devices). Regular current-voltage ( $I-V)$ protocols were used to assess astrocytic electrical properties. Current or voltage steps $(100 \mathrm{~ms})$ were implemented every $1 \mathrm{~s}$ with appropriate increments $(100-200 \mathrm{pA}$ or $5-10 \mathrm{mV}$, respectively, ranging from -120 to $+60 \mathrm{mV}$ ). The holding potential was selected in the range from -50 to $-80 \mathrm{mV}$ as the steady-state current approached zero. Brain slices were prepared from 13 and 9 GFAP-GFP mice at days 3 and 7 after infection, respectively, and 10 uninfected animals. Bridge balance (I-clamp) and capacitance compensation ( $V$-clamp) were performed, and pipette offset potential was compensated. Serial resistance in voltage-clamp mode was not compensated if improvement in recordings was not observed. All calculations were performed offline.

Cell input conductance $\left(G_{\mathrm{i}}\right)$ was calculated as the linear slope of $I-V$ curves using Clampfit-10 (Molecular Devices). The use of $I-V$ slopes represents the most precise method to calculate input conductance or resistance, because several recordings with different voltages and currents are included into the linear regression algorithm, which minimizes calculation errors (Karpuk and Vorobyov, 2003; Mishima et al., 2007; Karpuk and Hayar, 2008). Cell membrane capacitance $\left(C_{\mathrm{m}}\right)$ was calculated using the definition of time constant, $t=\mathrm{RC}$, where $t$ was the time constant calculated by the declining membrane potential at $5-20 \mathrm{mV}$ from resting membrane potential (RMP) (i.e., time point at $63 \%$ of maximal declination), whereas negative rectangular current steps were 
injected into cells by patch pipette. Alternatively, time constants were taken from the standard exponential fit of RMP declination (Clampfit-10) to independently confirm measurements. Both methods yielded similar results.

Quantitation of astrocyte coupling. As mentioned above, the GJ-permeable dye Alexa Fluor 350 was included in the patch pipette to visualize the degree of GJ communication in $\mathrm{GFAP}_{\mathrm{GFP}}{ }^{+}$astrocytes. Cells were analyzed immediately bordering the abscess margins extending over a distance of $1-1.5 \mathrm{~mm}$ to assess the effects of proximity to the inflammatory site on astrocyte GJ communication. Calculations of astrocyte coupling were performed by enumerating the number of superimposed cell images under appropriate filters for GFAP, Alexa Fluor 350, and SR101.

Estimation of hemichannel activity. Z-stack images using appropriate filters for GFP and $\mathrm{EtBr}$ visualization were captured before and during $\operatorname{EtBr}(2.5 \mu \mathrm{M})$ application in the bath solution at regions immediately bordering the brain abscess margins extending to $\sim 1 \mathrm{~mm}$ from the primary lesion as described above. A minimum of five images were acquired in every region over a series of time points spanning 30 min after EtBr application. The cell bodies of $\mathrm{GFAP}_{\mathrm{GFP}}{ }^{+}$astrocytes were marked as a region of interest (ROI), whereupon the maximal fluorescent intensity of $\mathrm{EtBr}$ in each ROI was plotted versus image acquisition time to calculate slope coefficients using a linear regression algorithm. Simultaneously, background slope coefficients were calculated from the same images as an average $\mathrm{EtBr}$ fluorescence intensity in three to five ROIs in which no EtBr staining or GFP expression was observed. The rate of EtBr uptake in arbitrary units per minute was calculated by subtracting background slope coefficients from cellular slope coefficients. Hemichannel involvement was evaluated by the ability of the connexon/ pannexon inhibitors carbenoxolone (Cbx), probenecid (Prob) (both from Sigma), the Cx43 mimetic peptide Gap26, and the Panx1 mimetic blocking peptide $\left({ }^{10} \mathrm{Panx} 1\right)$ (both from AnaSpec) to attenuate EtBr internalization. Brain slices were preincubated for $20 \mathrm{~min}$ with $\mathrm{Cbx}$ (50 $\mu \mathrm{M})$, Gap26 $(100 \mu \mathrm{M}),{ }^{10} \mathrm{Panx} 1(100 \mu \mathrm{M})$, or Prob $(500 \mu \mathrm{M})$ before EtBr application and were maintained in the presence of these inhibitors for 30 min after EtBr perfusion. Brain slices were prepared from GFAP-GFP mice at days $3(n=12)$ or $7(n=6)$ after infection or uninfected animals $(n=7)$ for EtBr uptake studies.

Immunofluorescence staining and quantitative measurements. Expression of Cx43, Cx30, Panx1, GLAST, and GLT-1 associated with brain abscesses was evaluated in the striatum of GFAP-GFP mice at days 3 ( $n=$ $6)$ or $7(n=5)$ after infection by immunofluorescence staining and confocal microscopy. Primary antibodies for Cx43 (catalog \#71-0700) and Cx30 (catalog \#71-2200) were visualized using an Alexa Fluor 594 anti-rabbit SFX kit (all from Invitrogen), whereas GLAST and GLT-1 (both polyclonal antibodies raised against synthetic peptides from the $\mathrm{C}$ termini of rat GLAST and GLT-1; Millipore Corporation) were detected using an anti-rat IgG-DyLight 649 conjugate (Jackson ImmunoResearch). Panxl was detected using a polyclonal antibody raised against the C-terminal cytoplasmic domain of the protein (Santa Cruz Biotechnology) and visualized using an anti-goat IgG-DyLight 649 conjugate (Jackson ImmunoResearch). Tissue sections were imaged using a Carl Zeiss LSM 510 META confocal microscope. For quantification of changes in Cx43, Cx30, Panx1, GLAST, and GLT-1 expression, mean fluorescent intensities were calculated from a series of ROIs extending outward from the brain abscess border. These values were normalized versus the mean fluorescent intensities measured from identical loca- tions in the contralateral uninfected striatum and are expressed as a percentage of fluorescent intensity.

Quantification of SR101 staining in astrocytes. To evaluate whether SR101 uptake/retention was influenced by hemichannel activity, brain slices from both uninfected mice and animals with brain abscesses at day 3 after infection were treated with Cbx to evaluate effects on SR101 staining. Briefly, brain slices from uninfected animals were continuously exposed to $\mathrm{Cbx}(50 \mu \mathrm{M})$ both during and after SR101 staining to evaluate effects on dye uptake. In separate experiments, brain slices from mice harboring brain abscess at day 3 after infection were stained with SR101 as described previously and incubated with $\mathrm{Cbx}(50 \mu \mathrm{M})$ during the last 10 min of SR101 staining and continuing until the end of the experiment. Images were captured within $1-2 \mathrm{~h}$ after the termination of SR101 staining. For quantitation, the cell body of each GFAP-GFP ${ }^{+}$astrocyte was identified as an ROI, and the maximum SR101 fluorescent intensity was calculated and normalized to the mean background fluorescent intensity taken in close proximity to each astrocyte with results reported in arbitrary units.

Statistical analysis. A Student's two-tailed $t$ test was used for all data analysis (MS Excel 2003), and values are reported as the mean \pm SEM acquired from several independent experiments.

\section{Results}

Characterization of astrocyte heterogeneity in brain abscesses In the current study, acute brain slices were analyzed from uninfected GFAP-GFP mice or animals harboring S. aureus-induced brain abscesses at either 3 or $7 \mathrm{~d}$ after infection. The brain abscess model was used as a tool to investigate the effects of a strong inflammatory insult on astrocyte physiology. These two time points were selected for analysis based on their ability to represent distinct stages of brain abscess evolution, namely acute cerebritis and edema (day 3 ) and resolution of overt edema and initiation 
A

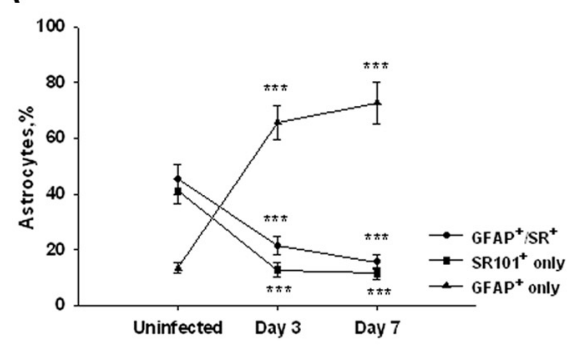

B

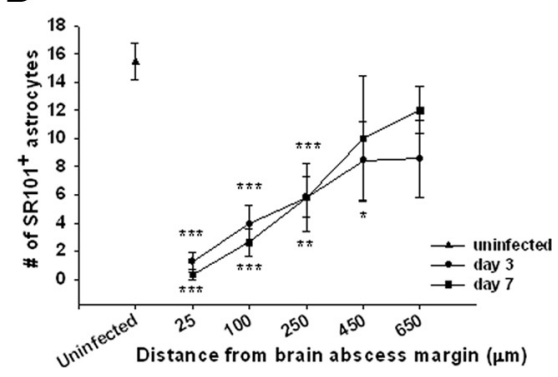

Figure 2. Inflammation alters astrocyte heterogeneity and SR101 uptake. A, Quantitation of astrocyte populations based on GFAP-GFP expression and/or SR101 staining in acute brain slices from the uninfected striatum and in abscesses at days 3 and 7 after infection. $\boldsymbol{B}$, Relationship between the numbers of $\mathrm{SR} 101^{+}$astrocytes in a given field of view versus distance from the brain abscess margins. Significant differences between uninfected and brain abscess groups at day 3 or 7 after infection are denoted by asterisks $\left({ }^{*} p<0.05,{ }^{* *} p<0.01,{ }^{* *} p<0.001\right)$. Acute brain slices from a total of 32 mice were used in these experiments. The data were obtained from a total of 437 astrocytes in uninfected slices and 727 and 889 astrocytes from slices at day 3 or 7 after infection, respectively.

of fibrotic wall formation surrounding the lesion (day 7). Both phases are associated with robust glial activation and peripheral immune cell recruitment (Baldwin and Kielian, 2004; Kielian, 2004, 2008). In addition, the infection elicits the expression of numerous proinflammatory mediators (Baldwin and Kielian, 2004; Kielian et al., 2007a,b), many of which have been reported to influence astrocyte GJ/hemichannel activity in vitro, including IL- $1 \beta$, TNF- $\alpha$, and nitric oxide (Bolaños and Medina, 1996; John et al., 1999; Retamal et al., 2007b; Haghikia et al., 2008). It is envisioned that the effects of the inflammatory milieu elicited during brain abscess formation on astrocyte activation may extend to other CNS inflammatory diseases, making this system an attractive model to query these interactions.

Acute brain slices from GFAP-GFP mice were used to facilitate astrocyte identification. In addition, slices were incubated with the astrocyte-selective dye SR101 (Nimmerjahn et al., 2004; Kafitz et al., 2008) as a supplementary marker to assess heterogeneity within the astrocyte compartment. Brain abscess morphology in an acute brain slice from a GFAP-GFP mouse is shown in Figure 1, which reveals centralized necrosis and nonspecific SR101 staining. In brain slices from uninfected GFAP_GFP mice, $45.3 \%$ of all astrocytes were both GFAP-GFP and SR101 positive $\left(\mathrm{GFAP}_{\mathrm{GFP}}{ }^{+} / \mathrm{SR} 101^{+}\right.$) (Fig. 2 A). However, astrocyte heterogeneity was also evident because $41.2 \%$ of astrocytes were only stained by SR101 (SR101 ${ }^{+}$only), whereas $13.5 \%$ exhibited only GFP fluorescence (GFAP-GFP ${ }^{+}$only). Not unexpectedly, the percentages of these astrocyte subtypes were significantly altered during brain abscess development. In particular, the percentages of GFAP-GFP single-positive astrocytes increased dramatically at both days $3(65.8 \%)$ and $7(72.9 \%)$ after infection $(p<0.001)$ (Fig. $2 A$ ). This result was expected because enhanced GFAP expression is indicative of reactive astrocytes, and previous studies from our group and others have established that astrocytes become activated both in vitro and in vivo in response to bacterial exposure (Baldwin and Kielian, 2004; Esen et al., 2004; Stenzel et al., 2004; Bloch et al., 2005). This shift toward a higher incidence of GFAP-GFP single-positive cells after infection was associated with a dramatic reduction in the percentage of SR $101^{+}$astrocytes (Fig. 2A). Collectively, these findings demonstrate the complexity of striatal astrocyte populations, a concept that is becoming more widely appreciated (Zhang and Barres, 2010).

Another interesting finding was related to the distribution of SR101 uptake in brain slices. An average of $15.5 \pm 1.3$ SR101 ${ }^{+}$ astrocytes were observed in the striatum of uninfected mice in a given FOV (Fig. 2 B). However, SR $101^{+}$astrocytes were rarely detected in regions immediately surrounding the abscess at either day $3(1.3 \pm$ $0.7 ; p<0.001)$ or day $7(0.3 \pm 0.3 ; p<$ $0.001)$ after bacterial infection. Although these cells were more frequent with increasing distance from the brain abscess margins, the number of SR $101^{+}$astrocytes did not reach the values observed in uninfected brain slices in regions $>550$ $\mu \mathrm{m}$ from the abscess border at either 3 or $7 \mathrm{~d}$ after infection (Fig. 2B). Therefore, there appears to be a relationship between the intensity of the inflammatory response and the extent of SR101 uptake in activated astrocytes in close proximity to the primary abscess.

\section{The inflammatory milieu attenuates GJ communication of GFAP-GFP ${ }^{+}$}

\section{astrocytes in a region-dependent manner}

Our previous report examining primary astrocytes in vitro demonstrated that $S$. aureus led to a significant reduction in astrocyte GJ communication (Esen et al., 2007). The objective of the current study was to determine the effects of neuroinflammation on astrocyte coupling properties in a more natural setting, i.e., acute brain slices. For these studies, whole-cell patch-clamp recordings were performed on GFAP-GFP ${ }^{+}$astrocytes to simultaneously acquire electrophysiological parameters in addition to introducing a GJ-permeable dye (i.e., Alexa Fluor 350). Although several astrocyte populations could be identified based on the differential expression/uptake of GFAP_GFP/SR101 (Fig. 2A), we elected to only study GJ communication in GFAP-GFP ${ }^{+}$cells, regardless of whether they were also SR $101^{+}$, to focus our experiments. In striatum from uninfected mice, the average number of cells exhibiting dye coupling from a single GFAP-GFP ${ }^{+}$astrocyte was $19.08 \pm 1.88$ (supplemental Fig. $1 A, B$, available at www. jneurosci.org as supplemental material). Importantly, the observed dye coupling in uninfected striatum was significantly inhibited by the bath application of the GJ blocker Cbx (1.7 \pm $0.37 ; p<0.001$ ), confirming the specificity of dye transfer through GJ channels (supplemental Fig. 1C,D, available at www. jneurosci.org as supplemental material). Notably, the extent of GJ communication was significantly decreased at both day 3 $(9.27 \pm 1.26 ; p<0.001)$ and day $7(9.16 \pm 1.7 ; p<0.001)$ after infection compared with astrocytes from uninfected striatum (supplemental Fig. $1 E-H$, available at www.jneurosci.org as supplemental material). However, only a portion of the cells demonstrating GJ coupling to GFAP-GFP ${ }^{+}$astrocytes could be positively identified as astrocytes based on either GFAP-GFP expression or SR101 staining. Specifically, $7.83 \pm 1.1$ of astrocytes in uninfected brain slices exhibited homocellular GJ communication, whereas the degree of astrocyte-astrocyte coupling was significantly reduced to $3.88 \pm 0.54$ cells on day $3(p<0.01)$ and $3.94 \pm 0.63$ on day $7(p<0.01)$ after infection (Fig. 3 ), confirming our previous in vitro studies with cultured astrocytes (Esen et al., 2007).

Because an inflammatory gradient is established during brain abscess development (i.e., higher levels of inflammatory mediators are present in the immediate vicinity of the abscess, which are diluted radiating outward from the lesion), we wanted to determine whether this gradient might lead to regional-dependent changes in astrocyte GJ communication. To examine this potential relationship, the degree of dye coupling was stratified based 


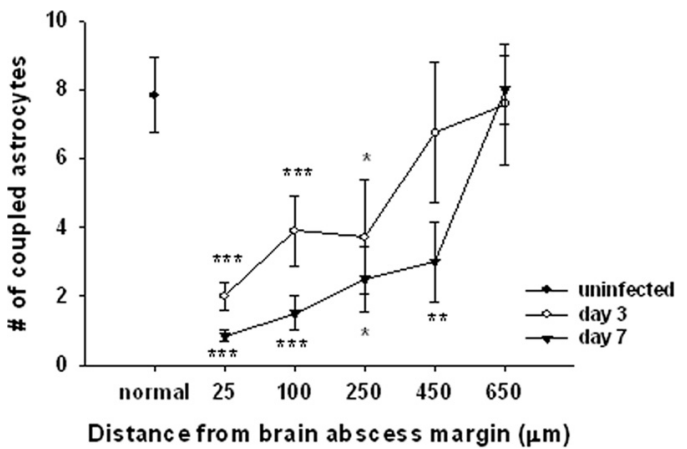

Figure 3. Inflammation leads to a regional-dependent reduction in astrocyte GJ communication. Brain abscesses were induced in GFAP-GFP mice, and the extent of GJ coupling was evaluated in GFAP-GFP ${ }^{+}$astrocytes in acute brain slices at day 3 or 7 after infection or uninfected animals. Significant differences between uninfected and brain abscess groups at day 3 or 7 after infection are denoted by asterisks $\left({ }^{*} p<0.05,{ }^{* *} p<0.01,{ }^{* * *} p<0.001\right)$. Gap junction coupling data were calculated from a total of 24 injected astrocytes in uninfected slices and 48 and 34 astrocytes from slices at day 3 or 7 after infection, respectively.

on the locations of individual GFAP- $\mathrm{GFP}^{+}$astrocytes from the brain abscess margins. Gap junction communication of GFAP$\mathrm{GFP}^{+}$astrocytes was minimal in close proximity to the abscess margins, whereas coupling gradually increased with increasing distance from the abscess proper, with values reaching those observed in uninfected tissue at distances $>550 \mu \mathrm{m}$ beyond the primary lesion (Fig. 3). This block in astrocyte GJ communication was most apparent at day 7 after infection and was widespread, affecting cells as far as $450 \mu \mathrm{m}$ from the abscess. These findings suggest that the inflammatory milieu generated during CNS bacterial infection leads to an astrocyte GJ gradient that adversely affects the ability of cells to form a syncytium nearby the primary inflammatory nidus. This GJ gradient could have a dramatic impact on the homeostasis of non-infected parenchyma surrounding the inflammatory site.

Hemichannel activity is transiently increased in GFAP-GFP ${ }^{+}$ astrocytes neighboring the inflammatory milieu

Recently, several studies have demonstrated hemichannel opening via $\mathrm{Cx} 43$ or Panx1 during ischemia and metabolic inhibition in vitro (Thompson et al., 2006; Bargiotas et al., 2009; Orellana et al., 2009) as well as an inverse relationship between GJ communication and hemichannel activity in astrocytes after exposure to lipopolysaccharide, a component of the outer cell wall of Gramnegative bacteria (Retamal et al., 2007b). Because we observed a dramatic reduction in astrocyte GJ communication nearby the primary abscess in which high concentrations of inflammatory mediators are present, we examined whether this microenvironment can affect hemichannel opening probability. Low levels of $\mathrm{EtBr}$ uptake were observed in GFAP- $\mathrm{GFP}^{+}$astrocytes in uninfected tissues (Fig. 4A), which has been reported by others under resting conditions (Contreras et al., 2003; Sáez et al., 2005). In contrast, GFAP-GFP ${ }^{+}$reactive astrocytes demonstrated a significant increase in EtBr uptake at day 3 after infection compared with uninfected tissues (Fig. $4 A$ ). The extent of EtBr uptake by astrocytes was maximal in regions nearest the abscess margins and gradually decreased with increasing distance from the lesion (Fig. 4A). However, hemichannel opening nearby the abscess was transient, because astrocytic EtBr uptake at day 7 after infection was either significantly lower or similar to that observed in uninfected tissues, which was also influenced in a region-dependent manner (Fig. 4A).
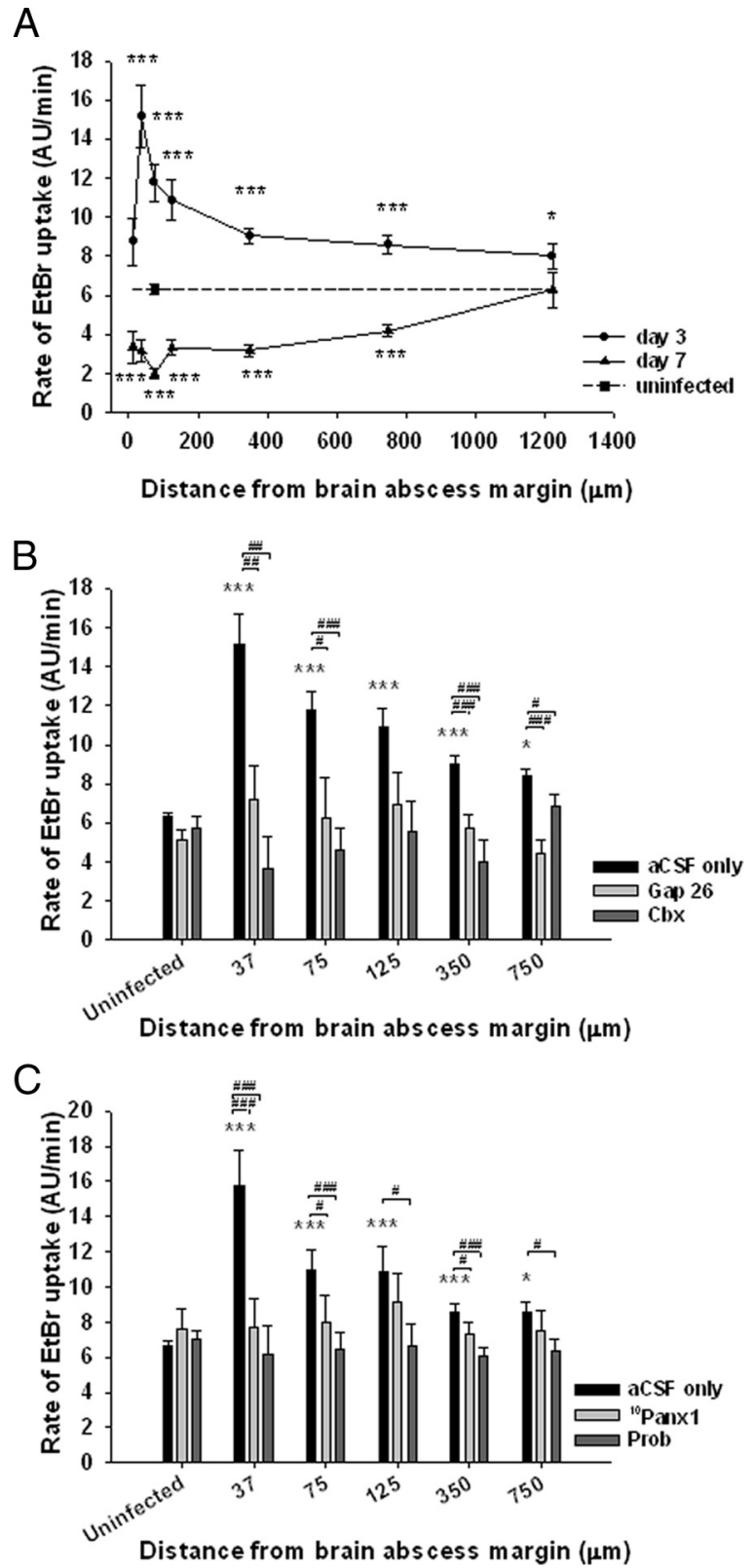

Figure 4. Hemichannel activity is increased in GFAP_GFP ${ }^{+}$astrocytes neighboring the inflammatory milieu in a region-dependent manner. Brain abscesses were induced in GFAP-GFP mice, and the extent of hemichannel activity was evaluated in GFAP-GFP ${ }^{+}$astrocytes in acute brain slices at day 3 or 7 after infection or uninfected animals by monitoring the rate of $\mathrm{EtBr}$ uptake. $\boldsymbol{A}$, Region-dependent rates of EtBr uptake by GFAP-GFP ${ }^{+}$astrocytes radiating outward from the brain abscess margins. The gap junction/hemichannel blockers Gap26 (100 $\mu \mathrm{M})$ and $\mathrm{Cbx}(50 \mu \mathrm{m})(\boldsymbol{B})$ as well as ${ }^{10} \operatorname{Panx} 1(100 \mu \mathrm{m})$ and $\operatorname{Prob}(500 \mu \mathrm{m})(\boldsymbol{C})$ reduced the rate of astrocyte EtBr uptake at day 3 after infection, confirming hemichannel activity. Significant differences between uninfected and brain abscess groups at day 3 or 7 after infection are denoted by asterisks $\left({ }^{*} p<0.05,{ }^{* * *} p<0.001\right)$, whereas alterations between slices incubated with Gap26, Cbx, ${ }^{10}$ Panx1, or Prob versus aCSF only are indicated by hatched signs ( ${ }^{\#} p<0.05$,

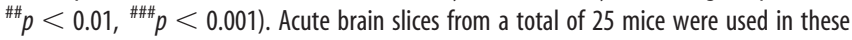
experiments. The data presented in $A$ were obtained from 418 astrocytes from uninfected slices and 627 and 289 astrocytes from slices at day 3 or 7 after infection, respectively. The data in $\boldsymbol{B}$ were calculated from 607 astrocytes in uninfected brain slices and from 855 astrocytes at day 3 after infection and in C from 996 astrocytes at day 3 after infection. AU, Arbitrary units.

To examine whether EtBr uptake by astrocytes was mediated through hemichannels, brain slices were treated with various inhibitors, including Cbx, the $\mathrm{Cx} 43$ mimetic peptide Gap26, the Panx1 mimetic peptide ${ }^{10} \mathrm{Panx} 1$, and Prob. Carbenoxolone is a 

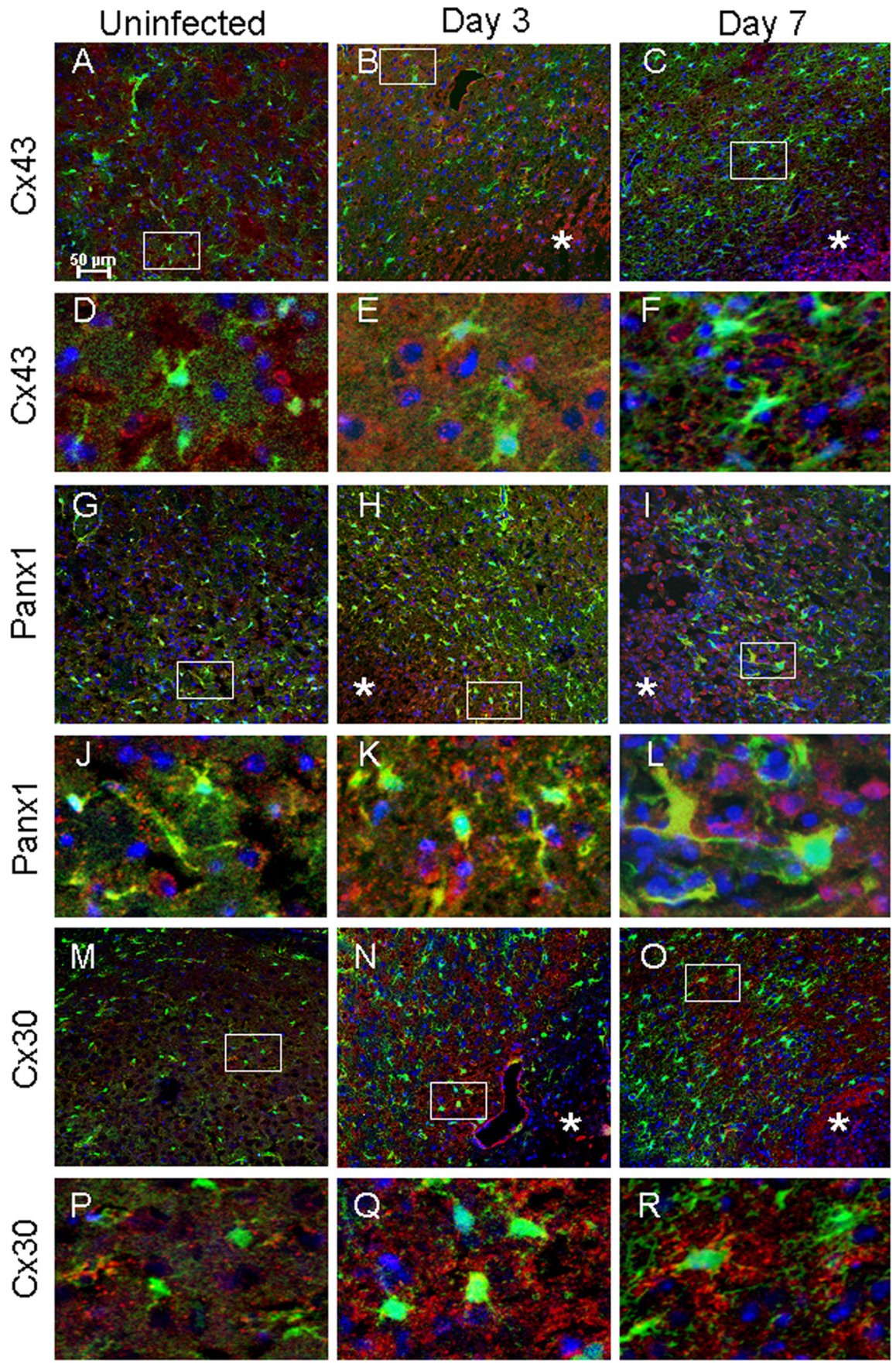

Figure 5. Inflammation alters $C \times 43$, Panx 1 , and $C \times 30$ expression in brain abscesses. Tissues from uninfected $(\boldsymbol{A}, \mathbf{D}, \mathbf{G}, \boldsymbol{J}, \boldsymbol{M}, \boldsymbol{P})$ GFAP-GFP mice or animals infected with $S$. aureus at either day $3(\boldsymbol{B}, \boldsymbol{E}, \boldsymbol{H}, \boldsymbol{K}, \boldsymbol{N}, \mathbf{Q})$ or $\mathbf{7}(\boldsymbol{C}, \boldsymbol{F}, \boldsymbol{I}, \boldsymbol{L}, \mathbf{O}, \boldsymbol{R})$ after infection were stained for $C x 43$, Panx1, or Cx30 (red) and 4', $6^{\prime}$-diamidino-2-phenylindole (DAPI) (blue), whereas GFAP-GFP ${ }^{+}$astrocytes are green and analyzed by confocal microscopy. Brain abscess margins are denoted with asterisks, and representative staining from the contralateral uninfected hemisphere is presented to assess basal expression in the striatum. The insets in $A-C$ represent areas of higher magnification that are presented in $\mathbf{D}-\boldsymbol{F}$, respectively, to demonstrate $\mathbf{C} 43$ cellular localization. Similarly, the insets in $\mathbf{G}-\boldsymbol{I}$ represent areas that are shown in $\boldsymbol{J}-\boldsymbol{L}$, respectively, to depict Panx 1 cellular localization, and the insets in $\mathbf{M} \mathbf{- 0}$ correspond to $\boldsymbol{P}-\boldsymbol{R}$ to represent $\mathrm{Cx} 30$ cellular localization.

strong and nonspecific blocker of both hemichannels and gap junction channels, whereas Gap26 has greater selectivity to inhibit hemichannels/gap junctions composed of $\mathrm{Cx} 43$ although recent evidence suggests that Gap26 can also modulate Panx1 hemichannels (Berthoud et al., 2004; Spray et al., 2006; Dahl, 2007). The Panx1 mimetic peptide ${ }^{10} \mathrm{Panx} 1$ has been reported to attenuate Panx1 currents, but it may also affect Cx46 currents
(Wang et al., 2007), whereas Prob has been reported as a more selective inhibitor for Panx1 hemichannels (Silverman et al., 2008; Ma et al., 2009). Both Cbx and Gap26 significantly decreased the rate of EtBr uptake by GFAP-GFP ${ }^{+}$astrocytes at day 3 after infection (Fig. $4 B$ ). In addition, ${ }^{10}$ Panx 1 and Prob also significantly reduced EtBr uptake in GFAP-GFP ${ }^{+}$astrocytes, with the most dramatic effects observed nearest the brain abscess margins in which the rate of EtBr uptake reached its maximal values (Fig. $4 C$ ). In contrast, none of the inhibitors examined significantly altered the rate of EtBr uptake in GFAP-GFP ${ }^{+}$astrocytes from uninfected brain slices (Fig. 4B,C), suggesting that this level of EtBr internalization could be attributed to nonspecific background levels or entry of dye via alternative transmembrane channels. Together, these data indicate that reactive astrocytes immediately bordering the abscess exhibit open hemichannels during the acute inflammatory period, which dissipates as the infection evolves.

Inflammation leads to changes in $\mathrm{Cx} 43$, Cx30, and Panx1 expression

To address whether the distance-dependent closure of GJ channels and/or hemichannel opening observed during acute neuroinflammation correlated with alterations in $\mathrm{Cx}$ and Panx levels, we examined Cx43, Cx30, and Panx1 protein expression during brain abscess development by immunofluorescence staining. Astrocytes robustly express $\mathrm{Cx} 43$ at all times, whereas in rodents older than 2 weeks of age, astrocytes can also express Cx30 and Cx26, albeit at lower levels (Dermietzel et al., 1991; Altevogt and Paul, 2004; Iacobas et al., 2004; Wiencken-Barger et al., 2007). Panx1 is expressed during development and primarily in neuronal populations in the adult; however, the majority of these studies have used mRNA expression techniques (Ray et al., 2005; Vogt et al., 2005; Zappalà et al., 2006). To our knowledge, no studies to date have demonstrated Panxl expression in astrocytes in vivo, although this has been shown by several groups in vitro (Huang et al., 2007; Zappalà et al., 2007; Iglesias et al., 2009). Regardless of the day after infection, Cx43, Cx30, and Panxl expression was concentrated around fine processes of GFAP-GFP ${ }^{+}$astrocytes, although some intracellular staining was also observed. Not surprisingly, there was a remarkable amount of $\mathrm{Cx} 43$ and Panx1 staining in GFAP-GFP-negative (GFAP-GFP ${ }^{-}$) cells associated with brain abscesses (Fig. 5). This is likely attributable to the well-appreciated fact that not all astrocytes are $\mathrm{GFAP}^{+}$(highlighted in Fig. $2 \mathrm{~A}$ ) in addition to the finding that alternative cell types have been reported to express 
Cx43 and/or Panx1, including macrophages/microglia (Eugenín et al., 2001, 2003; Garg et al., 2005) and neurons (Ray et al., 2005; Vogt et al., 2005; Zappalà et al., 2006; Zoidl et al., 2007). The expression of total Cx43 (in both GFAP-GFP ${ }^{+}$astrocytes and other cell types) was significantly increased at day 3 after infection over long distances extending from the primary abscess compared with the contralateral uninfected hemisphere from the same animals (Fig. 5) (supplemental Fig. 2A, available at www. jneurosci.org as supplemental material). This effect was transient because $\mathrm{Cx} 43$ levels returned to values equivalent in uninfected tissues by day 7 after infection (Fig. 5) (supplemental Fig. 2A, available at www. jneurosci.org as supplemental material). In contrast, Panxl expression was significantly elevated in brain abscess tissues at both days 3 and 7 after infection compared with contralateral uninfected striatum, and elevated Panxl was detected at distances exceeding $550 \mu \mathrm{m}$ from the primary abscess (Fig. 5) (supplemental Fig. 2B, available at www. jneurosci.org as supplemental material). In general, the enhanced expression of $\mathrm{Cx} 43$ and Panx1 associated with brain abscesses at day 3 correlated with the observed hemichannel activity. Expression of Cx30 was variable between animals harboring brain abscesses; however, despite this variation, significant increases in Cx30 expression were still identified at day 7 after infection in regions farthest removed from the abscess (supplemental Fig. 2B, available at www.jneurosci.org as supplemental material).

\section{Expression of glutamate transporters}

\section{is altered in astrocytes surrounding brain abscesses}

The alterations in astrocyte GJ coupling and hemichannel activity observed during the acute inflammatory period could conceivably disrupt astrocyte spatial buffering, which may translate into dysregulated glutamate concentrations in areas immediately neighboring the abscess (Parpura et al., 2004; Malarkey and Parpura, 2008; Matyash and Kettenmann, 2010). Therefore, expression of the astrocytic glutamate transporters GLT-1 and GLAST was examined to gain insights into the potential functional implications of neuroinflammation on activated astrocytes. GLAST was mainly associated with cell bodies and large processes, whereas GLT-1 staining was localized to numerous fine processes (Fig. 6). Both GFAP-GFP ${ }^{+}$and GFAP-GFP ${ }^{-}$cells exhibited GLAST and GLT-1 expression. Interestingly, during brain abscess development, many $\mathrm{GLAST}^{+}$cells displayed a non-astrocytic morphology, whereas GLT-1 expression remained associated with astrocyte-like cells (Fig. 6). GLAST levels were significantly increased in brain abscesses at both days 3 and 7 after infection compared with contralateral uninfected striatum (supplemental Fig. $3 A$, available at www. jneurosci.org as supplemental material). Similarly, a significant increase in GLT-1 expression was observed at day 3 after infection but was less dramatic at day 7 , although the overall levels of
GLT-1 expression remained significantly higher at day 3 after infection compared with contralateral striatum (supplemental Fig. 3B, available at www.jneurosci.org as supplemental material). These findings indicate that the inflammatory response generated during brain abscess formation dramatically impacts transporters responsible for glutamate trafficking, suggestive of cellular adaptation.

\section{Effects of inflammation on basic electrophysiological parameters of astrocytes}

Despite recent studies demonstrating that CNS injury can lead to perturbations in normal intrinsic properties of astrocytes (Schröder et al., 1999; Bordey et al., 2001; Anderová et al., 2004; Wang et al., 2008), little information is currently available regarding how inflammation per se modulates these parameters. Electrophysiological recordings of GFAP-GFP ${ }^{+}$astrocytes in acute brain slices revealed that the majority of significant differences in astrocytic parameters were observed between uninfected and brain abscess tissues at day 3 after infection (Table 1). Values for RMP $(-63.6 \pm 3.18$ and $-56.3 \pm 2.66 \mathrm{mV})$, capacitance $(41.4 \pm 6.96$ and $90.4 \pm 18.6 \mathrm{pF})$, and time constant $(1.03 \pm 0.11$ and $2.06 \pm$ $0.24 \mathrm{~ms}$ ) were all significantly increased in GFAP-GFP ${ }^{+}$astrocytes at day 3 compared with uninfected slices, respectively, and 
Table 1. Electrophysiological parameters of striatal GFAP-GFP ${ }^{+}$astrocytes

\begin{tabular}{lllclc}
\hline Measurement & Uninfected & $n$ & Abscess, day 3 PI & $n$ & Abscess, day 7 PI \\
\hline RMP $(\mathrm{mV})$ & $-63.6 \pm 3.18$ & 24 & $-56.3 \pm 2.66^{*}$ & 44 & $-62.6 \pm 3.19$ \\
$G_{\mathrm{i}}(\mathrm{nS})$ & $38.8 \pm 4.39$ & 24 & $42.0 \pm 3.23$ & 44 & $23.8 \pm 3.65^{\#}$ \\
Time constant (ms) & $1.02 \pm 0.11$ & 19 & $2.16 \pm 0.29^{* *}$ & 21 & 26 \\
$C_{m}$ (pF) & $41.4 \pm 6.96$ & 19 & $90.1 \pm 18.6^{*}$ & 21 & $1.40 \pm 0.33$ \\
\hline
\end{tabular}

PI, Postinfection. ${ }^{*} p<0.05$ and ${ }^{* *} p<0.01$ compared with cells from uninfected slices; ${ }^{\#} p<0.05$ compared with slices from day 3 after infection. Values presented represent the mean \pm SEM.

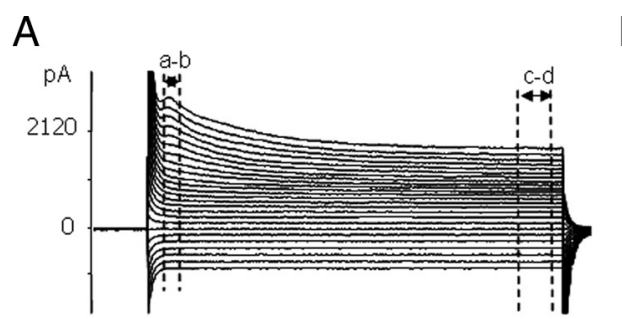

B

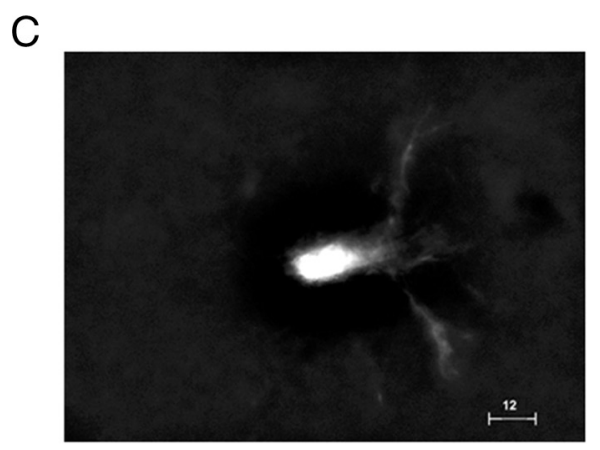

D

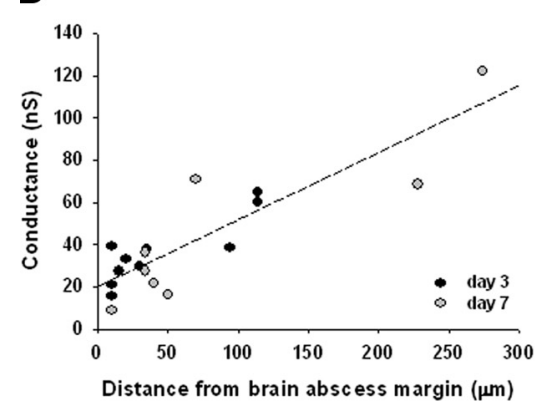

Figure 7. Methods for calculating $G_{i}$ and RMP. A, Whole-cell voltage-clamp recording in a striatal GFAP-GFP ${ }^{+}$complex astrocyte (morphology shown in $C$ ) located nearby an abscess. Dashed lines indicate the peak and steady-state current components ( $\boldsymbol{a}-\boldsymbol{b}$ and $\boldsymbol{c}-\boldsymbol{d}$, respectively) evoked by voltage steps (data not shown). Holding potential was $-80 \mathrm{mV}$. $\boldsymbol{B}$, Representative voltage-current plot for a striatal GFAP-GFP ${ }^{+}$astrocyte. Data points for current (picoamperes) and voltage (millivolts) were obtained by averaging corresponding segments $\boldsymbol{a}-\boldsymbol{b}$ and $\boldsymbol{c} \boldsymbol{d}$ delineated in $\boldsymbol{A}$. Cell conductance was taken as the linear regression slope near zero current (curved arrows). RMP $(-78 \mathrm{mV}$ ) was taken at zero current (straight arrows). C, Representative image of a striatal GFAP-GFP ${ }^{+}$astrocyte viewed with a DAPI filter after filling the cell with the gap junction-permeable dye Alexa Fluor 350 . $D$, Relationship between individual measurements of astrocyte conductance and distance from the brain abscess margin at day 3 or 7 after infection (correlation coefficient, 0.87 ; slope, $0.32 \pm 0.04 \mathrm{nS} / \mu \mathrm{m} ; n=18 ; p<0.01$ ).

partially recovered at day 7 after infection. Alterations in $C_{\mathrm{m}}$ were associated with changes in time constant rather than cell conductance. Therefore, the electrophysiological data suggest that astrocyte surface area may be increased at day 3 after infection, because capacitance is proportional to the area and the former was significantly elevated at day 3 after infection. However, we cannot exclude the possibility that capacitance may be increased as a result of astrocyte proliferation, which is typically associated with modifications in cell area. Indeed, it is well appreciated that cell hypertrophy is characteristic of reactive astrocytes, the latter of which is prevalent in regions immediately surrounding the abscess margins (Fig. 1).

Application of the GJ/hemichannel inhibitor Cbx in the bath medium decreased astrocyte conductance in uninfected brain slices compared with no treatment $(27.1 \pm 2.6 \mathrm{nS}, n=16$ and $38.8 \pm 4.39 \mathrm{nS}, n=24$, respectively; $p<0.05)$. Because Cbx did not affect hemichannel activity in untreated brain slices (Fig. $4 B$ ) but considerably reduced GJ coupling, this suggests that Cbx targets GJ channels. We also found that astrocyte conductance was minimal in close proximity to the brain abscess margins and increased in a distance-dependent pattern up to $300 \mu \mathrm{m}$ at both days 3 and 7 after infection (Fig. 7D). These data also support the possibility that astrocyte conductance was modulated by the closure of GJ but not hemichannels, because astrocyte GJ coupling was attenuated at both days 3 and 7 after infection (Fig. 3), whereas hemichannels were open at day 3 and closed at day 7 compared with uninfected tissues (Fig. 4A). Indeed, a positive correlation between astrocyte conductance and GJ coupling was observed (correlation coefficient, 0.69; slope, $2.64 \pm 0.6 \mathrm{nS} /$ cell; $n=23$; $p<0.01$ ) (supplemental Fig. 5, available at www. jneurosci.org as supplemental material). The slope value allows for an estimation of 24 GJ channels per coupled cell, given a unitary channel conductance of $110 \mathrm{pS}$, which has been reported for $\mathrm{Cx} 43$ (Contreras et al., 2003).

\section{Discussion}

Previous reports have described alterations in numerous astrocyte parameters in response to a variety of CNS injuries/ insults (Liberto et al., 2004; Giaume et al., 2007; Kielian, 2008). Despite these studies, little information is currently available describing how astrocytes adapt to an inflammatory milieu in vivo and how their electrical parameters may be altered. In the present study, we used a well-characterized model of brain abscess formation to establish a robust inflammatory nidus. This model is associated with overt glial activation and the global production of numerous inflammatory mediators, including IL- $1 \beta$, TNF- $\alpha$, and nitric oxide (Kielian et al., 2004, 2005, 2007a,b; Stenzel et al., 2005), each of which have been shown individually to attenuate astrocyte GJ communication and induce hemichannel activity in vitro (Bolaños and Medina, 1996; John et al., 1999; Retamal et al., 2007b; Haghikia et al., 2008). Our results demonstrate that GJ communication, hemichannel activity, and electrophysiological properties of GFAP-GFP ${ }^{+}$striatal astrocytes were significantly modified in the intact parenchyma surrounding brain abscesses. Interestingly, we observed that these changes occurred in a region-dependent manner radiating outward and in an opposite direction from the inflammatory gradient (Fig. 8). It is envisioned that the effects of inflammation in this model will extend to other CNS diseases with an inflammatory component.

A previous report from our laboratory demonstrated that $S$. aureus dramatically attenuates astrocyte GJ communication (Esen et al., 2007). The current data obtained with acute brain slices support these previous in vitro findings in which cell coupling was minimal in astrocytes closely associated with brain abscesses. Because hemichannel activity was also demonstrated at day 3 after infection, it remains possible that the GJ tracer Alexa 
Fluor 350 escaped loaded astrocytes via open hemichannels during this acute time point. However, this possibility appears less likely given the fact that images collected for GJ measurements were acquired within 2-5 min on cessation of dye loading, minimizing the likelihood of complete dye leakage via hemichannels. Importantly, we demonstrate that GJ communication is significantly inhibited in astrocytes neighboring the abscess at day 7 after infection, a time during which active hemichannels could not be demonstrated. Therefore, we propose that the reduction in GJ communication observed nearby brain abscesses at day 7 after infection is attributable solely to decreased dye transfer rather than leakage into the extracellular milieu. The precise mechanism leading to astrocytic GJ closure remains to be identified; however, it is known that GJs are closed by intracellular acidification and large transjunctional voltages (Moreno et al., 1994), which may be relevant in the intense inflammatory milieu.

Recent studies indicate that, under appropriate conditions, such as during inflammation, hemichannels are opened and facilitate the two-way communication between the intracellular and extracellular milieus (De Vuyst et al., 2007; Retamal et al., 2007b). Indeed, the inflammatory environment created during brain abscess formation led to the opening of hemichannels in GFAP_GFP ${ }^{+}$astrocytes immediately surrounding the lesion margins. Additional evidence of hemichannel activity was provided by the ability of Cbx, Gap26, ${ }^{10}$ Panx1, and Prob to inhibit EtBr uptake in GFAP-GFP ${ }^{+}$ astrocytes. Traditionally, both $\mathrm{Cbx}$ and Gap26 have been regarded to block GJ/hemichannels composed of Cxs; however, recent studies have demonstrated that both inhibitors are also capable of inhibiting dye uptake via Panxl hemichannels via a presumed steric effect (Dahl, 2007; Wang et al., 2007). In contrast, ${ }^{10}$ Panx 1 and Prob have been suggested as more "selective antagonists" of Panxl hemichannels (Ma et al., 2009). Despite this issue regarding hemichannel identification, to our knowledge, this study is the first to report hemichannel activity in situ and after a pathological insult to the intact CNS. Future studies that are beyond the scope of this initial report will use tissues from astrocyte-selective Cx43 and Panx1 null mice to definitively identify the composition of hemichannels that are activated during acute brain abscess formation.

The fluorescent dye SR101 is widely used as a specific astrocyte marker in brain slices (Nimmerjahn et al., 2004; Kafitz et al., 2008). Here we report a considerable reduction of striatal SR $101^{+}$astrocytes nearby the brain abscess border. In light of our findings demonstrating hemichannel activity at day 3 after infection, we predicted that this decrease in SR101 staining may result from dye leakage via open hemichannels. Indeed, this possibility was supported by additional experiments demonstrating that Cbx treatment led to SR101 retention in astrocytes immediately surrounding abscesses at day 3 after infection that were normally not labeled, whereas Cbx dramatically reduced SR101 staining in astrocytes from uninfected slices (supplemental Fig. 4, available at www.jneurosci.org as supplemental material). Importantly, SR101 has been shown to stain neurons in vivo via hemichannels that are opened during ischemic conditions (Thompson et al., 2006). To our knowledge, our study is the first to demonstrate the involvement of hemichannel activity for SR101 uptake/retention in astrocytes. However, it should be acknowledged that other mechanisms may also be responsible for the failure of SR101 to mark astrocytes in close proximity to brain abscesses.

Connexin hemichannels display a characteristic voltage sensitivity, typically being closed at RMP and opened during significant membrane depolarization (i.e., more than $+20 \mathrm{mV}$ ) (Trexler et al., 1996). The average RMP for GFAP-GFP ${ }^{+}$astrocytes at day 3 after infection when hemichannel activity was demonstrated was $-56.3 \pm 2.66 \mathrm{mV}$ (Table 1 ), well below the RMP reported for $\mathrm{Cx}$ hemichannel opening. In this regard, the complexity of the neuroinflammatory milieu should be acknowledged and conceivably hemichannel opening could be influenced by a multitude of factors, including extracellular divalent cation concentrations, extracellular ATP, and/or proinflammatory cytokines that have been shown to facilitate hemichannel opening in vitro (Retamal et al., 2007b; Iglesias et al., 2009). It is important to note that, in our studies, hemichannel activity was demonstrated in solutions containing extracellular $\mathrm{Ca}^{2+}$. Because low extracellular $\mathrm{Ca}^{2+}$ concentrations are required to open $\mathrm{Cx} 43$ hemichannels (Spray et al., 2006), it is unlikely that this factor was responsible for the hemichannel activity observed during acute brain abscess formation. 
It remains to be determined whether the changes in GJ communication and hemichannel activity associated with the inflammatory milieu exert beneficial or detrimental effects. Clearly, arguments can be made for either possibility. For example, decreases in GJ coupling may be beneficial to prevent the propagation of apoptotic stimuli (Rawanduzy et al., 1997; Frantseva et al., 2002; de Pina-Benabou et al., 2005), resulting in less cell death and maladaptive responses in distant tissues that are not directly impacted by the inflammatory milieu. Conversely, the lack of GJ communication may have a negative impact on the distribution of ions, glutamate, and other products in the inflammatory milieu that may exert toxic effects (Naus et al., 2001; Nakase et al., 2003, 2004; Lin et al., 2008). Without the benefit of gap junctions to dilute these molecules through the syncytium, astrocytes have to work in isolation to enhance their capacity to clear these factors. In this regard, we observed enhanced GLAST and GLT expression in brain abscesses as a possible attempt for glutamate utilization by astrocytes. However, in cases in which glutamate regulation is dysregulated, GLT can act in the reverse direction to release glutamate into the extracellular environment (Szatkowski et al., 1990). This is typically observed when membrane potentials are depolarized, which we observed in GFAP-GFP ${ }^{+}$astrocytes in intimate contact with the brain abscess (Table 1).

The elevated Cx43 and Panx1 levels observed during acute inflammation coincident with open hemichannels could be envisioned to have a beneficial impact on cell survival surrounding the abscess. For example, patent hemichannels may enhance astrocyte glutamate uptake and/or other noxious products for subsequent utilization. Conversely, persistent hemichannel opening will lead to the disruption of intracellular homeostasis, cell depolarization, and death. In addition, activation of Panx1 hemichannels has been shown to be important for inflammasome formation, which results in the processing of IL- $1 \beta$ into its active form (Pelegrin and Surprenant, 2006, 2009; Martinon et al., 2009). Ancillary evidence to support Panx1 hemichannel activity is provided by the dramatic production of IL- $1 \beta$ associated with brain abscesses (Kielian et al., 2004, 2007a), which has also been shown to inhibit astrocyte GJ communication in vitro (John et al., 1999). These changes, together with the observed increases in Cx43, Panx1, Cx30, GLAST, and GLT expression, speak to the fact that reactive astrocytes evolve and respond to their inflammatory environment. Indeed, a previous study has demonstrated a graded loss of $\mathrm{Cx} 43$ expression radiating from the site of ischemic injury (Li et al., 1998).

The relationship between GJ/hemichannels and electrophysiological properties of astrocytes remains an area of debate (Schools et al., 2006). Several studies have demonstrated alterations in GJ communication, RMP, and/or input resistance in activated astrocytes during such pathological conditions as mild ischemia (Wang et al., 2008), stab wound injury (Anderová et al., 2004), neocortical freeze injury (Bordey et al., 2001), or a unilateral lesion to the entorhinal cortex (Schröder et al., 1999). Astrocytes can be categorized as either passive or complex according to their electrophysiological patterns and expression of glutamate transporters or ionotropic glutamate receptors. For example, passive astrocytes exhibit low membrane resistance and a high degree of GJ communication, whereas complex cells display high membrane resistance and are not GJ coupled (Wallraff et al., 2004). Electrophysiological data in this study revealed intrinsic astrocytic changes during brain abscess development, and astrocyte heterogeneity was also noted. For example, numerous GFAP-GFP ${ }^{+}$astrocytes surrounding the abscess margins displayed complex membrane properties typified by decreased $G_{\mathrm{i}}$
(Fig. 7C,D), which differs from reports in normal striatum in which the majority of astrocytes exhibit passive characteristics (Adermark and Lovinger, 2008). The existence of complex astrocytes itself indicates that changes occur in response to the inflammatory milieu generated during brain abscess formation. These intrinsic modifications of GFAP-GFP ${ }^{+}$astrocytes occurred in parallel with decreases in GJ coupling and increases in hemichannel opening concomitant with increased membrane capacitance and cell depolarization. The latter could occur because of an inactivation of inwardly rectifying currents and/or activation of outwardly rectifying currents (Olsen and Sontheimer, 2008). Therefore, the intrinsic properties of astrocytes are influenced by their proximity to the inflammatory milieu as revealed by the data in our current study, which likely extends to alterations in function.

In summary, our results demonstrate a novel effect of the inflammatory environment on the differential regulation of astrocyte GJ communication versus hemichannel activity. An inverse correlation was observed with regard to the inflammatory gradient, which is highest nearest the abscess and inhibition of GJ coupling. In contrast, astrocytes immediately surrounding the abscess margins displayed transiently open hemichannels that could be inhibited by hemichannel blockers. This finding speaks to the fact that, during CNS pathology, the local inflammatory milieu leads to astrocyte changes that allows direct communication with the extracellular environment. The implications of these changes on the homeostasis/function of uninfected surrounding parenchyma and how they may influence CNS function currently remain unknown. The specific inflammatory mediator(s) responsible for modulating these changes in astrocyte GJ communication, hemichannel activity, and intrinsic properties during brain abscess development will be the subject of future studies.

\section{References}

Adermark L, Lovinger DM (2008) Electrophysiological properties and gap junction coupling of striatal astrocytes. Neurochem Int 52:1365-1372.

Altevogt BM, Paul DL (2004) Four classes of intercellular channels between glial cells in the CNS. J Neurosci 24:4313-4323.

Anderová M, Antonova T, Petrík D, Neprasová H, Chvátal A, Syková E (2004) Voltage-dependent potassium currents in hypertrophied rat astrocytes after a cortical stab wound. Glia 48:311-326.

Baldwin AC, Kielian T (2004) Persistent immune activation associated with a mouse model of Staphylococcus aureus-induced experimental brain abscess. J Neuroimmunol 151:24-32.

Baranova A, Ivanov D, Petrash N, Pestova A, Skoblov M, Kelmanson I, Shagin D, Nazarenko S, Geraymovych E, Litvin O, Tiunova A, Born TL, Usman N, Staroverov D, Lukyanov S, Panchin Y (2004) The mammalian pannexin family is homologous to the invertebrate innexin gap junction proteins. Genomics 83:706-716.

Bargiotas P, Monyer H, Schwaninger M (2009) Hemichannels in cerebral ischemia. Curr Mol Med 9:186-194.

Berthoud VM, Minogue PJ, Laing JG, Beyer EC (2004) Pathways for degradation of connexins and gap junctions. Cardiovasc Res 62:256-267.

Bloch O, Papadopoulos MC, Manley GT, Verkman AS (2005) Aquaporin-4 gene deletion in mice increases focal edema associated with staphylococcal brain abscess. J Neurochem 95:254-262.

Bolaños JP, Medina JM (1996) Induction of nitric oxide synthase inhibits gap junction permeability in cultured rat astrocytes. J Neurochem 66:2091-2099.

Bordey A, Lyons SA, Hablitz JJ, Sontheimer H (2001) Electrophysiological characteristics of reactive astrocytes in experimental cortical dysplasia. J Neurophysiol 85:1719-1731.

Chanson M, Derouette JP, Roth I, Foglia B, Scerri I, Dudez T, Kwak BR (2005) Gap junctional communication in tissue inflammation and repair. Biochim Biophys Acta 1711:197-207.

Contreras JE, Sánchez HA, Eugenin EA, Speidel D, Theis M, Willecke K, 
Bukauskas FF, Bennett MV, Sáez JC (2002) Metabolic inhibition induces opening of unapposed connexin 43 gap junction hemichannels and reduces gap junctional communication in cortical astrocytes in culture. Proc Natl Acad Sci U S A 99:495-500.

Contreras JE, Sáez JC, Bukauskas FF, Bennett MV (2003) Functioning of cx43 hemichannels demonstrated by single channel properties. Cell Commun Adhes 10:245-249.

Cruz NF, Ball KK, Dienel GA (2007) Functional imaging of focal brain activation in conscious rats: impact of $\left[{ }^{14} \mathrm{C}\right]$ glucose metabolite spreading and release. J Neurosci Res 85:3254-3266.

Dahl G (2007) Gap junction-mimetic peptides do work, but in unexpected ways. Cell Commun Adhes 14:259-264.

de Pina-Benabou MH, Szostak V, Kyrozis A, Rempe D, Uziel D, UrbanMaldonado M, Benabou S, Spray DC, Federoff HJ, Stanton PK, Rozental $\mathrm{R}$ (2005) Blockade of gap junctions in vivo provides neuroprotection after perinatal global ischemia. Stroke 36:2232-2237.

Dermietzel R, Hertberg EL, Kessler JA, Spray DC (1991) Gap junctions between cultured astrocytes: immunocytochemical, molecular, and electrophysiological analysis. J Neurosci 11:1421-1432.

De Vuyst E, Decrock E, Cabooter L, Dubyak GR, Naus CC, Evans WH, Leybaert L (2006) Intracellular calcium changes trigger connexin 32 hemichannel opening. EMBO J 25:34-44.

De Vuyst E, Decrock E, De Bock M, Yamasaki H, Naus CC, Evans WH, Leybaert L (2007) Connexin hemichannels and gap junction channels are differentially influenced by lipopolysaccharide and basic fibroblast growth factor. Mol Biol Cell 18:34-46.

D'hondt C, Ponsaerts R, De Smedt H, Bultynck G, Himpens B (2009) Pannexins, distant relatives of the connexin family with specific cellular functions? BioEssays 31:953-974.

Dubyak GR (2009) Both sides now: multiple interactions of ATP with pannexin-1 hemichannels. Focus on "A permeant regulating its permeation pore: inhibition of pannexin 1 channels by ATP.” Am J Physiol Cell Physiol 296:C235-C241.

Esen N, Tanga FY, DeLeo JA, Kielian T (2004) Toll-like receptor 2 (TLR2) mediates astrocyte activation in response to the Gram-positive bacterium Staphylococcus aureus. J Neurochem 88:746-758.

Esen N, Shuffield D, Syed MM, Kielian T (2007) Modulation of connexin expression and gap junction communication in astrocytes by the grampositive bacterium S. aureus. Glia 55:104-117.

Eugenín EA, Eckardt D, Theis M, Willecke K, Bennett MV, Saez JC (2001) Microglia at brain stab wounds express connexin 43 and in vitro form functional gap junctions after treatment with interferon-gamma and tumor necrosis factor-alpha. Proc Natl Acad Sci U S A 98:4190-4195.

Eugenín EA, Brañes MC, Berman JW, Sáez JC (2003) TNF-alpha plus IFNgamma induce connexin43 expression and formation of gap junctions between human monocytes/macrophages that enhance physiological responses. J Immunol 170:1320-1328.

Figiel M, Allritz C, Lehmann C, Engele J (2007) Gap junctional control of glial glutamate transporter expression. Mol Cell Neurosci 35:130-137.

Frantseva MV, Kokarovtseva L, Naus CG, Carlen PL, MacFabe D, Perez Velazquez JL (2002) Specific gap junctions enhance the neuronal vulnerability to brain traumatic injury. J Neurosci 22:644-653.

Gandhi GK, Cruz NF, Ball KK, Theus SA, Dienel GA (2009) Selective astrocytic gap junctional trafficking of molecules involved in the glycolytic pathway: impact on cellular brain imaging. J Neurochem 110:857-869.

Garg S, Md Syed M, Kielian T (2005) Staphylococcus aureus-derived peptidoglycan induces $\mathrm{Cx} 43$ expression and functional gap junction intercellular communication in microglia. J Neurochem 95:475-483.

Giaume C, Kirchhoff F, Matute C, Reichenbach A, Verkhratsky A (2007) Glia: the fulcrum of brain diseases. Cell Death Differ 14:1324-1335.

Haghikia A, Ladage K, Lafênetre P, Haghikia A, Hinkerohe D, Smikalla D, Haase CG, Dermietzel R, Faustmann PM (2008) Intracellular application of TNF-alpha impairs cell to cell communication via gap junctions in glioma cells. J Neurooncol 86:143-152.

Harris AL (2007) Connexin channel permeability to cytoplasmic molecules. Prog Biophys Mol Biol 94:120-143.

Hinkerohe D, Smikalla D, Haghikia A, Heupel K, Haase CG, Dermietzel R, Faustmann PM (2005) Effects of cytokines on microglial phenotypes and astroglial coupling in an inflammatory coculture model. Glia 52:85-97.

Houades V, Koulakoff A, Ezan P, Seif I, Giaume C (2008) Gap junction- mediated astrocytic networks in the mouse barrel cortex. J Neurosci 28:5207-5217.

Huang Y, Grinspan JB, Abrams CK, Scherer SS (2007) Pannexinl is expressed by neurons and glia but does not form functional gap junctions. Glia 55:46-56.

Iacobas DA, Scemes E, Spray DC (2004) Gene expression alterations in connexin null mice extend beyond the gap junction. Neurochem Int 45:243-250.

Iglesias R, Dahl G, Qiu F, Spray DC, Scemes E (2009) Pannexin 1: the molecular substrate of astrocyte "hemichannels." J Neurosci 29:7092-7097.

John GR, Scemes E, Suadicani SO, Liu JS, Charles PC, Lee SC, Spray DC, Brosnan CF (1999) IL-1beta differentially regulates calcium wave propagation between primary human fetal astrocytes via pathways involving P2 receptors and gap junction channels. Proc Natl Acad Sci U S A 96:11613-11618.

Kafitz KW, Meier SD, Stephan J, Rose CR (2008) Developmental profile and properties of sulforhodamine 101-labeled glial cells in acute brain slices of rat hippocampus. J Neurosci Methods 169:84-92.

Karpuk N, Hayar A (2008) Activation of postsynaptic GABAB receptors modulates the bursting pattern and synaptic activity of olfactory bulb juxtaglomerular neurons. J Neurophysiol 99:308-319.

Karpuk N, Vorobyov V (2003) Spike sequences and mean firing rate in rat neocortical neurons in vitro. Brain Res 973:16-30.

Kielian T (2004) Immunopathogenesis of brain abscess. J Neuroinflammation $1: 16$.

Kielian T (2008) Glial connexins and gap junctions in CNS inflammation and disease. J Neurochem 106:1000-1016.

Kielian T, Barry B, Hickey WF (2001) CXC chemokine receptor-2 ligands are required for neutrophil-mediated host defense in experimental brain abscesses. J Immunol 166:4634-4643.

Kielian T, Bearden ED, Baldwin AC, Esen N (2004) IL-1 and TNF-alpha play a pivotal role in the host immune response in a mouse model of Staphylococcus aureus-induced experimental brain abscess. J Neuropathol Exp Neurol 63:381-396.

Kielian T, Haney A, Mayes PM, Garg S, Esen N (2005) Toll-like receptor 2 modulates the proinflammatory milieu in Staphylococcus aureus-induced brain abscess. Infect Immun 73:7428-7435.

Kielian T, Phulwani NK, Esen N, Syed MM, Haney AC, McCastlain K, Johnson J (2007a) MyD88-dependent signals are essential for the host immune response in experimental brain abscess. J Immunol 178:4528-4537.

Kielian T, Esen N, Liu S, Phulwani NK, Syed MM, Phillips N, Nishina K, Cheung AL, Schwartzman JD, Ruhe JJ (2007b) Minocycline modulates neuroinflammation independently of its antimicrobial activity in Staphylococcus aureus-induced brain abscess. Am J Pathol 171:1199-1214.

Konietzko U, Müller CM (1994) Astrocytic dye coupling in rat hippocampus: topography, developmental onset, and modulation by protein kinase C. Hippocampus 4:297-306.

Li WE, Ochalski PA, Hertzberg EL, Nagy JI (1998) Immunorecognition, ultrastructure and phosphorylation status of astrocytic gap junctions and connexin 43 in rat brain after cerebral focal ischaemia. Eur J Neurosci 10:2444-2463.

Liberto CM, Albrecht PJ, Herx LM, Yong VW, Levison SW (2004) Proregenerative properties of cytokine-activated astrocytes. J Neurochem 89:1092-1100.

Lin JH, Lou N, Kang N, Takano T, Hu F, Han X, Xu Q, Lovatt D, Torres A, Willecke K, Yang J, Kang J, Nedergaard M (2008) A central role of connexin 43 in hypoxic preconditioning. J Neurosci 28:681-695.

Ma W, Hui H, Pelegrin P, Surprenant A (2009) Pharmacological characterization of pannexin-1 currents expressed in mammalian cells. J Pharmacol Exp Ther 328:409-418.

Malarkey EB, Parpura V (2008) Mechanisms of glutamate release from astrocytes. Neurochem Int 52:142-154.

Martinon F, Mayor A, Tschopp J (2009) The inflammasomes: guardians of the body. Annu Rev Immunol 27:229-265.

Matyash V, Kettenmann H (2010) Heterogeneity in astrocyte morphology and physiology. Brain Res Rev 63:2-10.

Même W, Calvo CF, Froger N, Ezan P, Amigou E, Koulakoff A, Giaume C (2006) Proinflammatory cytokines released from microglia inhibit gap junctions in astrocytes: potentiation by beta-amyloid. FASEB J 20:494-496.

Mishima T, Sakatani S, Hirase H (2007) Intracellular labeling of single cortical astrocytes in vivo. J Neurosci Methods 166:32-40. 
Moreno AP, Rook MB, Fishman GI, Spray DC (1994) Gap junction channels: distinct voltage-sensitive and -insensitive conductance states. Biophys J 67:113-119.

Nakase T, Fushiki S, Naus CC (2003) Astrocytic gap junctions composed of connexin 43 reduce apoptotic neuronal damage in cerebral ischemia. Stroke 34:1987-1993.

Nakase T, Söhl G, Theis M, Willecke K, Naus CC (2004) Increased apoptosis and inflammation after focal brain ischemia in mice lacking connexin 43 in astrocytes. Am J Pathol 164:2067-2075.

Naus CC, Ozog MA, Bechberger JF, Nakase T (2001) A neuroprotective role for gap junctions. Cell Commun Adhes 8:325-328.

Nimmerjahn A, Kirchhoff F, Kerr JN, Helmchen F (2004) Sulforhodamine 101 as a specific marker of astroglia in the neocortex in vivo. Nat Methods $1: 31-37$.

Nolte C, Matyash M, Pivneva T, Schipke CG, Ohlemeyer C, Hanisch UK, Kirchhoff F, Kettenmann H (2001) GFAP promoter-controlled EGFPexpressing transgenic mice: a tool to visualize astrocytes and astrogliosis in living brain tissue. Glia 33:72-86.

Olsen ML, Sontheimer H (2008) Functional implications for Kir4.1 channels in glial biology: from $\mathrm{K}+$ buffering to cell differentiation. J Neurochem 107:589-601.

Orellana JA, Sáez PJ, Shoji KF, Schalper KA, Palacios-Prado N, Velarde V, Giaume C, Bennett MV, Sáez JC (2009) Modulation of brain hemichannels and gap junction channels by pro-inflammatory agents and their possible role in neurodegeneration. Antioxid Redox Signal 11:369-399.

Parpura V, Scemes E, Spray DC (2004) Mechanisms of glutamate release from astrocytes: gap junction "hemichannels," purinergic receptors and exocytotic release. Neurochem Int 45:259-264.

Paxinos G, Franklin K (2001) The mouse brain in stereotaxic coordinates, Ed 2. San Diego: Academic.

Pelegrin P, Surprenant A (2006) Pannexin-1 mediates large pore formation and interleukin-1beta release by the ATP-gated P2X7 receptor. EMBO J 25:5071-5082.

Pelegrin P, Surprenant A (2009) The P2X(7) receptor-pannexin connection to dye uptake and IL-1beta release. Purinergic Signal 5:129-137.

Qiu F, Dahl G (2009) A permeant regulating its permeation pore: inhibition of pannexin 1 channels by ATP. Am J Physiol Cell Physiol 296:C250-C255.

Rawanduzy A, Hansen A, Hansen TW, Nedergaard M (1997) Effective reduction of infarct volume by gap junction blockade in a rodent model of stroke. J Neurosurg 87:916-920.

Ray A, Zoidl G, Weickert S, Wahle P, Dermietzel R (2005) Site-specific and developmental expression of pannexin 1 in the mouse nervous system. Eur J Neurosci 21:3277-3290.

Retamal MA, Schalper KA, Shoji KF, Bennett MV, Sáez JC (2007a) Opening of connexin 43 hemichannels is increased by lowering intracellular redox potential. Proc Natl Acad Sci U S A 104:8322-8327.

Retamal MA, Froger N, Palacios-Prado N, Ezan P, Sáez PJ, Sáez JC, Giaume C (2007b) Cx43 hemichannels and gap junction channels in astrocytes are regulated oppositely by proinflammatory cytokines released from activated microglia. J Neurosci 27:13781-13792.

Rose CR, Ransom BR (1997) Gap junctions equalize intracellular $\mathrm{Na}^{+}$concentration in astrocytes. Glia 20:299-307.

Rouach N, Koulakoff A, Abudara V, Willecke K, Giaume C (2008) Astroglial metabolic networks sustain hippocampal synaptic transmission. Science 322:1551-1555.

Sáez JC, Retamal MA, Basilio D, Bukauskas FF, Bennett MV (2005) Connexin-based gap junction hemichannels: gating mechanisms. Biochim Biophys Acta 1711:215-224.

Scemes E, Suadicani SO, Dahl G, Spray DC (2007) Connexin and pannexin mediated cell-cell communication. Neuron Glia Biol 3:199-208.

Schools GP, Zhou M, Kimelberg HK (2006) Development of gap junctions in hippocampal astrocytes: evidence that whole cell electrophysiological phenotype is an intrinsic property of the individual cell. J Neurophysiol 96:1383-1392.

Schröder W, Hager G, Kouprijanova E, Weber M, Schmitt AB, Seifert G, Steinhäuser C (1999) Lesion-induced changes of electrophysiological properties in astrocytes of the rat dentate gyrus. Glia 28:166-174.

Shintani-Ishida K, Uemura K, Yoshida K (2007) Hemichannels in cardiomyocytes open transiently during ischemia and contribute to reperfusion injury following brief ischemia. Am J Physiol Heart Circ Physiol 293:H1714-H1720.

Sifri CD, Park J, Helm GA, Stemper ME, Shukla SK (2007) Fatal brain abscess due to community-associated methicillin-resistant Staphylococcus aureus strain USA300. Clin Infect Dis 45:e113-e117.

Silverman WR, de Rivero Vaccari JP, Locovei S, Qiu F, Carlsson SK, Scemes E, Keane RW, Dahl G (2009) The pannexin 1 channel activates the inflammasome in neurons and astrocytes. J Biol Chem 284:18143-18151.

Silverman W, Locovei S, Dahl G (2008) Probenecid, a gout remedy, inhibits pannexin 1 channels. Am J Physiol Cell Physiol 295:C761-C767.

Spray DC, Ye ZC, Ransom BR (2006) Functional connexin "hemichannels": a critical appraisal. Glia 54:758-773.

Stenzel W, Soltek S, Schlüter D, Deckert M (2004) The intermediate filament GFAP is important for the control of experimental murine Staphylococcus aureus-induced brain abscess and Toxoplasma encephalitis. J Neuropathol Exp Neurol 63:631-640.

Stenzel W, Soltek S, Miletic H, Hermann MM, Körner H, Sedgwick JD, Schlüter D, Deckert M (2005) An essential role for tumor necrosis factor in the formation of experimental murine Staphylococcus aureus-induced brain abscess and clearance. J Neuropathol Exp Neurol 64:27-36.

Sutor B, Hagerty T (2005) Involvement of gap junctions in the development of the neocortex. Biochim Biophys Acta 1719:59-68.

Szatkowski M, Barbour B, Attwell D (1990) Non-vesicular release of glutamate from glial cells by reversed electrogenic glutamate uptake. Nature 348:443-446.

Tabernero A, Medina JM, Giaume C (2006) Glucose metabolism and proliferation in glia: role of astrocytic gap junctions. J Neurochem 99:1049-1061.

Thompson RJ, Macvicar BA (2008) Connexin and pannexin hemichannels of neurons and astrocytes. Channels (Austin) 2:81-86.

Thompson RJ, Zhou N, MacVicar BA (2006) Ischemia opens neuronal gap junction hemichannels. Science 312:924-927.

Trexler EB, Bennett MV, Bargiello TA, Verselis VK (1996) Voltage gating and permeation in a gap junction hemichannel. Proc Natl Acad Sci U S A 93:5836-5841.

Vogt A, Hormuzdi SG, Monyer H (2005) Pannexin1 and Pannexin2 expression in the developing and mature rat brain. Brain Res Mol Brain Res 141:113-120.

Wallraff A, Odermatt B, Willecke K, Steinhäuser C (2004) Distinct types of astroglial cells in the hippocampus differ in gap junction coupling. Glia 48:36-43.

Wang J, Ma M, Locovei S, Keane RW, Dahl G (2007) Modulation of membrane channel currents by gap junction protein mimetic peptides: size matters. Am J Physiol Cell Physiol 293:C1112-C1119.

Wang LP, Cheung G, Kronenberg G, Gertz K, Ji S, Kempermann G, Endres M, Kettenmann H (2008) Mild brain ischemia induces unique physiological properties in striatal astrocytes. Glia 56:925-934.

Wiencken-Barger AE, Djukic B, Casper KB, McCarthy KD (2007) A role for Connexin43 during neurodevelopment. Glia 55:675-686.

Ye ZC, Wyeth MS, Baltan-Tekkok S, Ransom BR (2003) Functional hemichannels in astrocytes: a novel mechanism of glutamate release. J Neurosci 23:3588-3596.

Yen MR, Saier MH Jr (2007) Gap junctional proteins of animals: the innexin/pannexin superfamily. Prog Biophys Mol Biol 94:5-14.

Zappalà A, Cicero D, Serapide MF, Paz C, Catania MV, Falchi M, Parenti R, Pantò MR, La Delia F, Cicirata F (2006) Expression of pannexin1 in the CNS of adult mouse: cellular localization and effect of 4-aminopyridineinduced seizures. Neuroscience 141:167-178.

Zappalà A, Li Volti G, Serapide MF, Pellitteri R, Falchi M, La Delia F, Cicirata V, Cicirata F (2007) Expression of pannexin2 protein in healthy and ischemized brain of adult rats. Neuroscience 148:653-667.

Zhang Y, Barres BA (2010) Astrocyte heterogeneity: an underappreciated topic in neurobiology. Curr Opin Neurobiol 20:588-594.

Zhuo L, Sun B, Zhang CL, Fine A, Chiu SY, Messing A (1997) Live astrocytes visualized by green fluorescent protein in transgenic mice. Dev Biol 187:36-42.

Zoidl G, Petrasch-Parwez E, Ray A, Meier C, Bunse S, Habbes HW, Dahl G, Dermietzel R (2007) Localization of the pannexin1 protein at postsynaptic sites in the cerebral cortex and hippocampus. Neuroscience 146:9-16. 